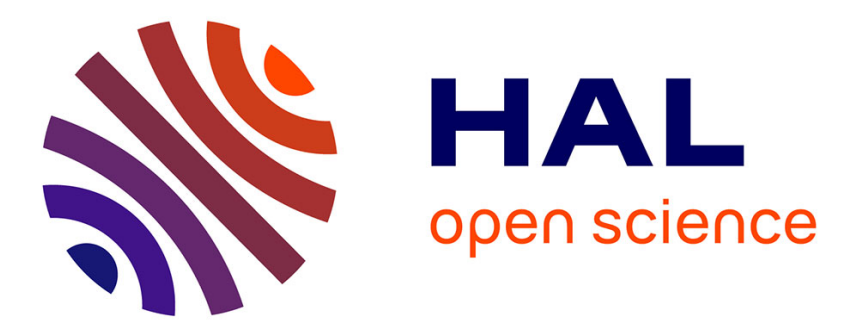

\title{
Cascaded Predictive Controller design for speed control and Load Torque rejection of Induction Motor
}

\author{
Adel Merabet, Hichem Arioui, Ouhrouche Mohand
}

\section{To cite this version:}

Adel Merabet, Hichem Arioui, Ouhrouche Mohand. Cascaded Predictive Controller design for speed control and Load Torque rejection of Induction Motor. American Control Conference (ACC 2008), Jun 2008, Seattle, WA, United States. pp.1139-1144, 10.1109/ACC.2008.4586646 . hal-00342960

\section{HAL Id: hal-00342960 \\ https://hal.science/hal-00342960}

Submitted on 29 Sep 2009

HAL is a multi-disciplinary open access archive for the deposit and dissemination of scientific research documents, whether they are published or not. The documents may come from teaching and research institutions in France or abroad, or from public or private research centers.
L'archive ouverte pluridisciplinaire HAL, est destinée au dépôt et à la diffusion de documents scientifiques de niveau recherche, publiés ou non, émanant des établissements d'enseignement et de recherche français ou étrangers, des laboratoires publics ou privés. 


\title{
Cascaded Predictive Controller Design for Speed Control and Load Torque Rejection of Induction Motor
}

\author{
Adel Merabet, Hichem Arioui and Mohand Ouhrouche
}

\begin{abstract}
Cascaded nonlinear predictive controller for induction motor drive is presented. The load torque, considered as an unknown disturbance, is rejected using a disturbance observer. First, a nonlinear multivariable predictive controller is applied to track electromagnetic torque and rotor flux norm trajectories. Then, a speed predictive control strategy is carried out from the electromechanical equation of the machine. Both controllers are applied in a cascade structure to induction motor. The prediction model is carried out via Taylor series expansion using Lie derivatives for nonlinear model. The derived predictive law minimizes a quadratic performance index of the predicted tracking error for multivariable system and a predicted error for speed control. The implementation of the cascaded control law does not need an on line optimization and the tracking of desired trajectories is achieved successfully. The load torque observer, derived from the speed predictive control, is simplified to a PI structure. This observer structure guarantees the disturbance rejection and the robustness to parameters variations. Simulation results show the high performance of the proposed control scheme.
\end{abstract}

\section{INTRODUCTION}

$\mathrm{I}_{\mathrm{n}}^{\mathrm{N}}$ NDUCTION motor (IM) compared to other types of electric machines, exhibits several advantages such as lower cost, reliability, simplicity and less maintenance. However, it is highly nonlinear multivariable and, contrary to DC motor for example, requires more complex methods of control. One of the most significant developments in the control area has been the field oriented control (FOC) proposed by Blaschke [1]. This technique is very useful except that it is very sensitive to parameters variation. To improve FOC, several techniques have been proposed such as full linearizing state feedback control based on differential geometric, direct torque control, sliding mode control, predictive control [2-4]. Even though, these techniques bring improvements to FOC, the research area is open especially for unknown disturbance compensation and robustness to machine parameter.

Model based predictive control (MPC) has received a

Manuscript received Mars 3, 2008. This work was supported in part by the French Research Agency (ANR), in the Framework of VIGISIM Project.

A. Merabet and M. Ouhrouche are with the Applied Sciences Department, University of Quebec at Chicoutimi, Canada (phone: 1418 545-5011; fax: 1 418-545-5012; e-mails: Adel_Merabet@uqac.ca, mouhrouc@uqac.ca).

H. Arioui, is with UFR Sciences et Technologies, Université d'Evry Val d'Essonne, France (phone: 33169477564; fax: 33169477599; e-mail: hichem.arioui@ibisc.fr). great deal of attention and is considered by many to be one of the most promising methods in control engineering [57]. It has been extended to nonlinear system [8-10]. The predictive control is applied to induction motor drive with good performance for trajectories tracking [11-14]. However, the performance accuracy is affected by load torque, which is not always known in industrial applications, and the machine parameters uncertainties. To overcome this problem, an estimation of the load torque is done in this paper for compensation of its unknown variations, which constitutes the contribution of this work. The load torque observer can be derived from the predictive control law. The observer has PI structure, where the integral action allows the elimination of the steady state error and enhances the robustness of the control scheme with respect to model uncertainties and disturbances rejection.

\section{INDUCTION MOTOR MODEL}

The continuous time model of the IM is done in stator reference frame $(\alpha-\beta)$. Under the assumption of linearity of the magnetic circuit, the nonlinear affine form can be expressed as

$$
\begin{aligned}
& \&(t)=\mathbf{f}(\mathbf{x})+\mathbf{g}(\mathbf{x}) \mathbf{u}(t) \\
& \text { where } \\
& \mathbf{x}=\left[\begin{array}{lllll}
i_{s \alpha} & i_{s \beta} & \phi_{r \alpha} & \phi_{r \beta} & \omega
\end{array}\right]^{T} \\
& \mathbf{u}=\left[\begin{array}{lll}
u_{s \alpha} & u_{s \beta}
\end{array}\right]^{T}
\end{aligned}
$$

The state $\mathbf{x}$ belongs to the set $\boldsymbol{\Omega}=\left\{\mathbf{x} \in \mathfrak{R}^{\mathbf{5}}: \phi_{r \alpha}^{2}+\phi_{r \beta}^{2} \neq 0\right\}$

Vector function $\mathbf{f}(\mathbf{x})$ is defined as follows

$$
\mathbf{f}(\mathbf{x})=\left[\begin{array}{c}
-\gamma i_{s \alpha}+\frac{K}{T_{r}} \phi_{r \alpha}+p K \omega \phi_{r \beta} \\
-\gamma i_{s \beta}+\frac{K}{T_{r}} \phi_{r \beta}-p K \omega \phi_{r \alpha} \\
\frac{L_{m}}{T_{r}} i_{s \alpha}-\frac{1}{T_{r}} \phi_{r \alpha}-p \omega \phi_{r \beta} \\
\frac{L_{m}}{T_{r}} i_{s \beta}-\frac{1}{T_{r}} \phi_{r \beta}+p \omega \phi_{r \alpha} \\
\frac{p L_{m}}{J L_{r}}\left(\phi_{r \alpha} i_{s \beta}-\phi_{r \beta} i_{s \alpha}\right)-\frac{f_{r}}{J} \omega
\end{array}\right]
$$

g is a constant matrix 
$\mathbf{g}=\left[\begin{array}{ll}g_{1} & g_{2}\end{array}\right]=\left[\begin{array}{ccccc}\frac{1}{\sigma L_{s}} & 0 & 0 & 0 & 0 \\ 0 & \frac{1}{\sigma L_{s}} & 0 & 0 & 0\end{array}\right]^{T}$

The outputs to be controlled are the electromagnetic torque and the squared rotor flux norm

$\mathbf{y}=\mathbf{h}(\mathbf{x})=\left[\begin{array}{c}y_{1}=h_{1}=p \frac{L_{m}}{L_{r}}\left(\phi_{r \alpha} i_{s \beta}-\phi_{r \beta} i_{s \alpha}\right) \\ y_{2}=h_{2}=\phi_{r}^{2}=\phi_{r \alpha}^{2}+\phi_{r \beta}^{2}\end{array}\right]$

\section{NONLINEAR PREDictive CONTROL}

The optimal control is carried out through the minimization of the receding performance index defined as

$$
\mathfrak{J}(\mathbf{x}, \mathbf{u})=\frac{1}{2} \int_{\tau_{1}}^{\tau_{2}}\left(\mathbf{y}(t+\tau)-\mathbf{y}_{\mathbf{r}}(t+\tau)\right)^{T}\left(\mathbf{y}(t+\tau)-\mathbf{y}_{\mathbf{r}}(t+\tau)\right) d \tau
$$

The control weighting term is not included in the performance index (3). However, the control effort can be achieved by adjusting the minimum and maximum prediction times $\tau_{1}$ and $\tau_{2}$ respectively [9].

The $\tau$-step ahead prediction of the system outputs is obtained via Taylor series expansion.

$$
\begin{aligned}
y_{i}(t+\tau)= & h_{i}(\mathbf{x})+\tau L_{\mathbf{f}} h_{i}(\mathbf{x})+\frac{\tau^{2}}{2 !} L_{\mathbf{f}}^{2} h_{i}(\mathbf{x})+\ldots+\frac{\tau^{r_{i}}}{r_{i} !} L_{\mathbf{f}}^{r_{i}} h_{i}(\mathbf{x}) \\
& +\frac{\tau^{r_{i}}}{r_{i} !} L_{\mathrm{g}} L_{\mathbf{f}}^{\left(r_{i}-1\right)} h_{i}(\mathbf{x}) \mathbf{u}(t)
\end{aligned}
$$

The following notation is used for the Lie derivative of the function $h_{j}(\mathbf{x})$ along a vector field $\mathbf{f}(\mathbf{x})=\left[f_{1}(\mathbf{x}) \ldots f_{n}(\mathbf{x})\right]^{T}$

$$
L_{\mathbf{f}} h_{j}=\sum_{i=1}^{n} \frac{\partial h_{j}}{\partial x_{i}} f_{i}(\mathbf{x})=\frac{\partial h_{j}}{\partial \mathbf{x}} \mathbf{f}(\mathbf{x})
$$

Iteratively, we have

$$
\begin{aligned}
& L_{\mathrm{f}}^{k} h_{j}=L_{\mathrm{f}}\left(L_{\mathrm{f}}^{(k-1)} h_{j}\right) \\
& L_{g} L_{\mathrm{f}} h_{j}=\frac{\partial L_{\mathrm{f}} h_{j}}{\partial \mathbf{x}} g(\mathbf{x})
\end{aligned}
$$

For torque output, the relative degree is $r_{1}=1$

$$
\left\{\begin{array}{l}
y_{1}(t)=h_{1}(\mathbf{x}) \\
\&(t)=L_{\mathbf{f}} h_{1}(\mathbf{x})+L_{g_{1}} h_{1}(\mathbf{x}) u_{s \alpha}(t)+L_{g_{2}} h_{1}(\mathbf{x}) u_{s \beta}(t)
\end{array}\right.
$$

$$
\left\{\begin{array}{l}
y_{2}(t)=h_{2}(\mathbf{x}) \\
\mathscr{L}_{2}(t)=L_{\mathbf{f}} h_{2}(\mathbf{x}) \\
(t)=L_{\mathbf{f}}^{2} h_{2}(\mathbf{x})+L_{g_{1}} L_{\mathbf{f}} h_{2}(\mathbf{x}) u_{s \alpha}(t)+L_{g_{2}} L_{\mathbf{f}} h_{2}(\mathbf{x}) u_{s \beta}(t)
\end{array}\right.
$$

The expansion of the induction motor outputs $\mathbf{y}(t+\tau)$ in $r_{i}^{\text {th }}$ (with $r_{1}=1$ and $r_{2}=2$ ) order Taylor series under matrix form is

$$
\mathbf{y}(t+T)=\prod(\mathbf{Y}(\mathbf{x})+\mathbf{H}(\mathbf{x}) \mathbf{u}(t))
$$

where

$\Pi=\left[\begin{array}{lll}I_{2 \times 2} & T^{*} I_{2 \times 2} & \left(T^{2} / 2\right) * I_{2 \times 2}\end{array}\right]$

$\mathbf{Y}(\mathbf{x})=\left[\begin{array}{lllllll}h_{1}(\mathbf{x}) & h_{2}(\mathbf{x}) & L_{\mathrm{f}} h_{1}(\mathbf{x}) & L_{\mathrm{f}} h_{2}(\mathbf{x}) & 0 & L_{\mathrm{f}}^{2} h_{2}(\mathbf{x})\end{array}\right]^{T}$

$\mathbf{H}(\mathbf{x})=\left[\begin{array}{llllll}0 & 0 & L_{g_{1}} h_{1}(\mathbf{x}) & 0 & 0 & L_{g_{1}} L_{\mathbf{f}} h_{2}(\mathbf{x}) \\ 0 & 0 & L_{g_{2}} h_{1}(\mathbf{x}) & 0 & 0 & L_{g_{2}} L_{\mathbf{f}} h_{2}(\mathbf{x})\end{array}\right]^{T}$

$I_{. \times .}$: identity matrix.

The predicted reference $\mathbf{y}_{\mathbf{r}}(t+\tau)$ can be approximated by Taylor series expansion, and given by

$$
\mathbf{y}_{\mathbf{r}}(t+\tau)=\prod \mathbf{Y}_{\mathbf{r}}(t)
$$

where

$\mathbf{Y}_{\mathbf{r}}(t)=\left[\begin{array}{llllll}y_{r_{1}}(t) & y_{r_{2}}(t) & \&_{r_{1}}(t) & \&_{r_{2}}(t) & 0 & \&_{r_{2}}(t)\end{array}\right]^{T}$

The performance index (3) can be simplified as

$\mathfrak{I}=\frac{1}{2}\left[\mathbf{Y}(\mathbf{x})+\mathbf{H}(\mathbf{x}) \mathbf{u}(t)-\mathbf{Y}_{\mathbf{r}}(t)\right]^{T} \bar{\Pi}\left[\mathbf{Y}(\mathbf{x})+\mathbf{H}(\mathbf{x}) \mathbf{u}(t)-\mathbf{Y}_{\mathbf{r}}(t)\right]$

where

$$
\bar{\Pi}=\int_{\tau_{1}}^{\tau_{2}} \Pi^{T} \Pi d \tau
$$

The necessary condition of optimal control is given by

$$
\frac{\partial \mathfrak{I}}{\partial \mathbf{u}}=0
$$

Then, the optimal nonlinear control law, which minimizes the receding horizon performance index (3), is given by

$$
\mathbf{u}(t)=\left(\mathbf{H}^{T}(\mathbf{x}) \bar{\Pi} \mathbf{H}(\mathbf{x})\right)^{-1} \mathbf{H}^{T}(\mathbf{x}) \bar{\Pi}\left(\mathbf{Y}_{\mathbf{r}}(t)-\mathbf{Y}(\mathbf{x})\right)
$$

\section{SPEEd PREdictive CONTROL}

The mechanical dynamic of IM is described by

$\cos (t)=-\frac{f_{r}}{J} \omega(t)+\frac{1}{J} T_{e}(t)-\frac{1}{J} T_{L}(t)$

where, 
$T_{e}=p \frac{L_{m}}{L_{r}}\left(\phi_{r \alpha} i_{s \beta}-\phi_{r \beta} i_{s \alpha}\right)$ and considered as control input.

$T_{L}$ is the load torque, which is considered as an unknown disturbance in the system dynamics.

A simple predictive control algorithm is carried out for this system, which consists of applying a control that allows the tracking error of speed to reach zero.

$\omega(t+\tau)-\omega_{r}(t+\tau)=0$

The predicted speed $\omega(t+\tau)$ is carried out by Taylor series expansion

$$
\begin{aligned}
\omega\left(t+\tau_{r}\right) & =\omega(t)+\tau \& \&(t) \\
& =\omega(t)+\tau\left(-\frac{f_{r}}{J} \omega(t)+\frac{1}{J} T_{e}(t)-\frac{1}{J} T_{L}(t)\right)
\end{aligned}
$$

Similarly, The predicted reference speed $\omega_{r}(t+\tau)$ is approximated as

$\omega_{r}(t+\tau)=\omega_{r}(t)+\tau \alpha_{r}(t)(17)$

The optimal control is carried out from (15), (16) and (17). It is given by

$$
T_{e}(t)=-\frac{J}{\tau}\left(\omega(t)-\omega_{r}(t)\right)+f_{r} \omega(t)+J \phi_{r}(t)+T_{L}(t)
$$

The cascaded control structure of IM system is obtained by using the torque, calculated from the speed control law, as reference torque for the nonlinear predictive controller developed above. Thus, the initial system can be decomposed into two subsystems in cascaded form. The inner loop incorporates torque-flux model and the external loop is the equation of the mechanical dynamics of motor.

\section{LOAD TORQUE COMPENSATION}

The accuracy of the speed control law for trajectory tracking needs the knowledge about the load torque. Since $T_{L}$ is an unknown variable, it should be estimated in the controller as $\hat{T}_{L}$ in order to eliminate the effects of disturbance.

In this paper, a load torque observer is introduced for estimating $T_{L}$. In order to simplify the design of the observer, since there is no information about the load torque and the observer period in the actual system is short enough compared with the variation of $T_{L}$, it is possible to make the following assumption:

$\frac{d T_{L}}{d t}=0$
It follows from (14) that

$-\frac{1}{J} T_{L}(t)=\cos (t)+\frac{f_{r}}{J} \omega(t)-\frac{1}{J} T_{e}(t)$

An initial disturbance observer is given by

$\left.f_{L}^{\&}(t)=p_{0} \frac{1}{J} \hat{T}_{L}+p_{0}(c \& t)+\frac{f_{r}}{J} \omega(t)-\frac{1}{J} T_{e}(t)\right)$

where $p_{0}$ is a parameter to be chosen.

The observation error is given by

$e(t)=T_{L}(t)-\hat{T}_{L}(t)$

Then, the error dynamics is given by

$$
\begin{aligned}
\mathscr{\&}(t) & =T_{L}^{\&}(t)-T_{L}^{\&}(t) \\
& =p_{0} \frac{1}{J}\left(T_{L}(t)-\hat{T}_{L}(t)\right)=p_{0} \frac{1}{J} e(t)
\end{aligned}
$$

$p_{0}$ must be chosen negative such that the system

$\&(t)-p_{0} \frac{1}{J} e(t)=0$

is exponentially stable.

The load torque $T_{L}$ is replaced by its estimation $\hat{T}_{L}$ in the control law (18)

$$
T_{e}(t)=-\frac{J}{\tau}\left(\omega(t)-\omega_{r}(t)\right)+f_{r} \omega(t)+J \&_{\psi}(t)+\hat{T}_{L}(t)
$$

Then, the control law (25) is embedded into the disturbance observer (21)

$$
\left.f_{L}^{\&}(t)=p_{0}(\operatorname{cst} t)-\cos _{r}(t)\right)+\frac{p_{0}}{\tau}\left(\omega(t)-\omega_{r}(t)\right)
$$

Integrating (26), we get

$$
\hat{T}_{L}(t)=p_{0}\left(\omega(t)-\omega_{r}(t)\right)+\frac{p_{0}}{\tau} \int_{0}^{t}\left(\omega(\tau)-\omega_{r}(\tau)\right) d \tau
$$

The load torque disturbance observer has a PI structure, which compensates the unknown load torque and enhances the robustness for the speed tracking.

\section{ROTOR FLUX ESTIMATOR}

The rotor flux estimator, used in this work, is carried out from the Kalman filter (KF) applied to the $4^{\text {th }}$ order discrete 
linear time varying model depending on the measured speed

$$
\left\{\begin{array}{l}
\mathbf{x}(k+1)=A(k) \mathbf{x}(k)+B(k) \mathbf{u}(k)+\mathbf{w}(k) \\
\mathbf{y}(k)=C \mathbf{x}(k)+\mathbf{v}(k)
\end{array}\right.
$$

where

$$
\begin{aligned}
& \mathbf{x}(k)=\left[\begin{array}{llll}
i_{s \alpha}(k) & i_{s \beta}(k) & \phi_{r \alpha}(k) & \phi_{r \beta}(k)
\end{array}\right]^{T} \\
& \mathbf{u}(k)=\left[\begin{array}{ll}
u_{s \alpha}(k) & u_{s \beta}(k)
\end{array}\right]^{T} \\
& \mathbf{y}(k)=\left[\begin{array}{ll}
i_{s \alpha}(k) & i_{s \beta}(k)
\end{array}\right]^{T}
\end{aligned}
$$

$\mathbf{w}(k)$ and $\mathbf{v}(k)$ are independent noises with covariance

$E\left\{\mathbf{w}(k) \mathbf{w}(k)^{T}\right\}=Q, E\left\{\mathbf{v}(k) \mathbf{v}(k)^{T}\right\}=R$

Discrete time Kalman filter equations

$\hat{\mathbf{x}}(k+1 / k)=A(k) \hat{\mathbf{x}}(k / k)+B(k) \mathbf{u}(k)$

$P(k+1 / k)=A(k) P(k / k) A(k)^{T}+Q$

$K(k+1)=P(k+1 / k) C^{T}\left(C P(k+1 / k) C^{T}+R\right)^{-1}$

$\hat{\mathbf{x}}(k+1 / k+1)=\hat{\mathbf{x}}(k+1 / k)+K(k+1)(\mathbf{y}(k+1)-C \hat{\mathbf{x}}(k+1 / k))$

$P(k+1 / k+1)=(I-K(k+1) C) P(k+1 / k)$

Initial conditions

$\hat{\mathbf{x}}_{0}=E\left\{\mathbf{x}_{0}\right\} ; \quad P_{0}=E\left\{\left(\mathbf{x}_{0}-\hat{\mathbf{x}}_{0}\right)\left(\mathbf{x}_{0}-\hat{\mathbf{x}}_{0}\right)^{T}\right\}$

The matrices $A, B$ and $C$ are carried out from the discretization of the continuous model of induction motor.

$$
\begin{gathered}
A(k)=\left[\begin{array}{cccc}
1-T_{s} \gamma & 0 & \frac{T_{s} K}{T_{r}} & T_{s} p K \omega(k) \\
0 & 1-T_{s} \gamma & -T_{s} p K \omega(k) & \frac{T_{s} K}{T_{r}} \\
\frac{T_{s} L_{m}}{T_{r}} & 0 & 1-\frac{T_{s}}{T_{r}} & -T_{s} p \omega(k) \\
0 & \frac{T_{s} L_{m}}{T_{r}} & T_{s} p \omega(k) & 1-\frac{T_{s}}{T_{r}}
\end{array}\right] \\
B=\left[\begin{array}{cccc}
\frac{T_{s}}{\sigma L_{s}} & 0 & 0 & 0 \\
0 & T & C
\end{array}\right]^{T} \quad C=\left[\begin{array}{cccc}
1 & 0 & 0 & 0 \\
0 & 1 & 0 & 0
\end{array}\right]
\end{gathered}
$$

where

$T_{s}$ is the sampling time.

Fig. 1 shows the proposed control scheme for the induction motor drive.

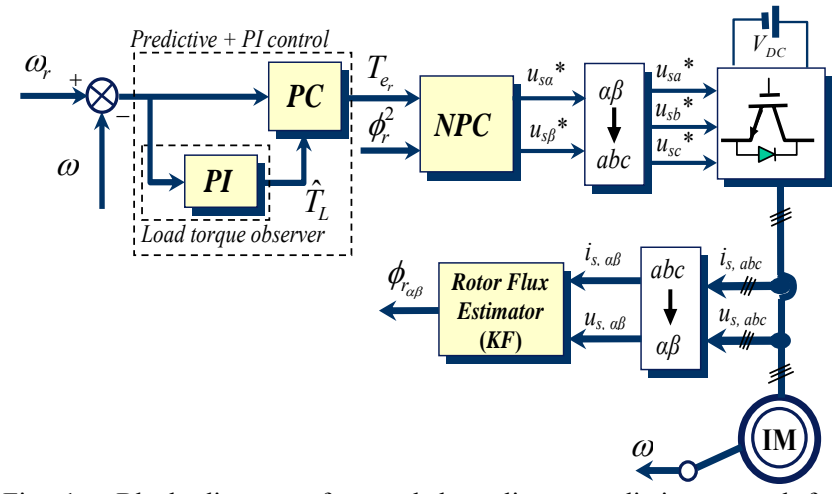

Fig. 1. Block diagram of cascaded nonlinear predictive control for induction motor drive

\section{SimUlation RESUlTS}

The simulations have been carried out to verify the performance of the proposed cascaded controller. The details about the motor are given in appendix.

The digital model of the motor is run with sample time $T_{s}=1 \mu \mathrm{s}$. The modulation time of the SV PWM is $T_{m}=100$ $\mu \mathrm{s}$. The information about the rotor speed is assumed to be known by measurement, the rotor flux is estimated by Kalman filter with sample time $T_{s}=5 \mu \mathrm{s}$. The sample time of the controller is $T_{s}=100 \mu \mathrm{s}$, the prediction times for inner controller are chosen as $\tau_{1}=0, \tau_{2}=10^{*} T_{s}=1 \mathrm{~ms}$ and for external controller $\tau=50 * T_{s}=5 \mathrm{~ms}$ and $p_{0}=-5$.

First, the machine controlled by the cascaded control law is run with the nominal values of the machine parameters. The tracking performances for rotor speed and rotor flux norm are shown in Fig. 2 and 3 respectively. The noise, shown in flux estimation, occurs from the different sample times used in simulation. Fig. 4 gives the estimation of the load torque. As shown in results, the tracking performance is achieved successfully.
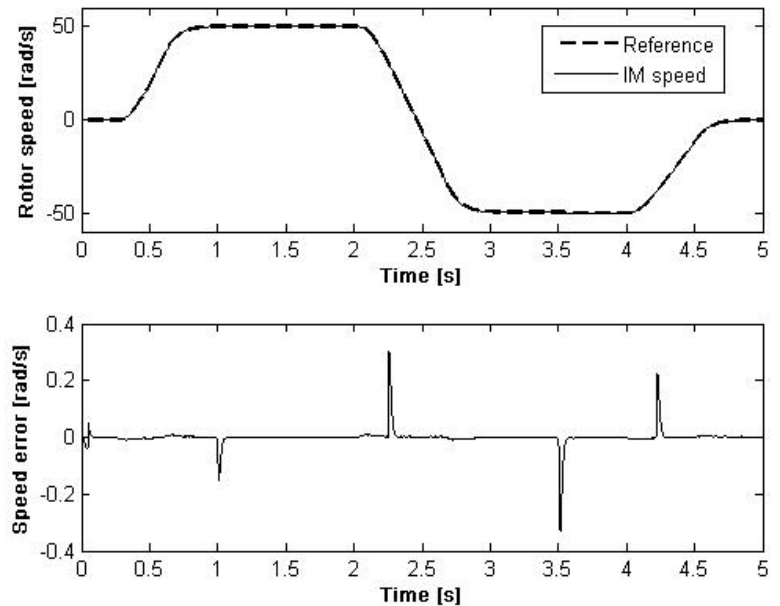

Fig. 2. Rotor speed and speed error responses of induction motor drive
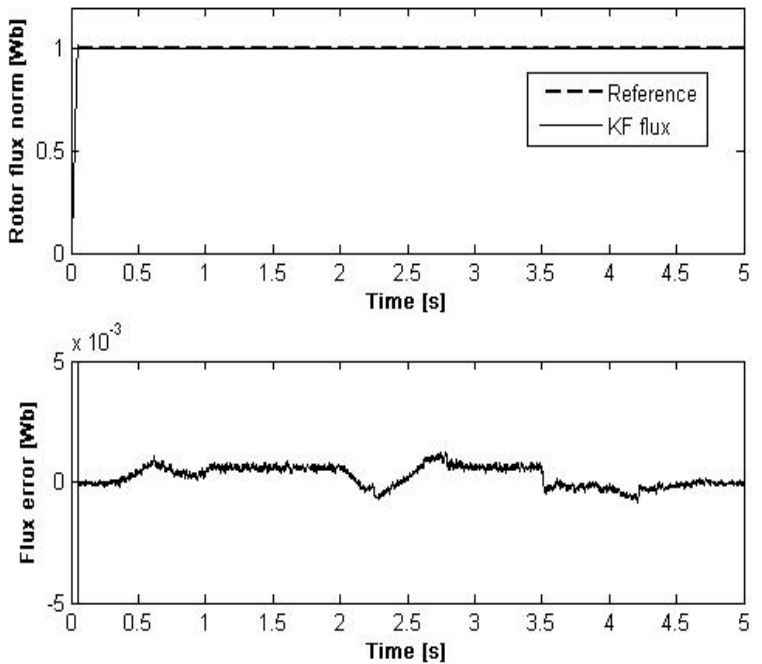

Fig. 3. Rotor flux norm and flux error responses of induction motor drive 


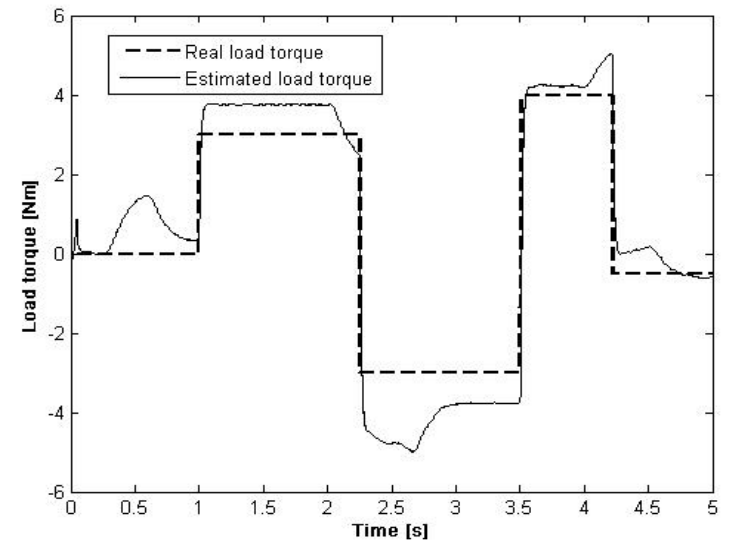

Fig. 4. Load torque estimation

Then, in case of mismatched model, the rotor resistance $\left(R_{r}\right)$ is varied as shown in Fig. 5. This variation is not taken into account when the control law is carried out. The nominal value of the rotor resistance is used in the control law computation. The same prediction times as above are used in this simulation. The tracking performances for speed and flux norm with smooth speed reference are shown in Fig. 6 and 7 respectively, and Fig. 8 gives the estimated load torque. These results show that the robustness to $R_{r}$ variation is achieved by this controller. However, the accuracy of the load torque estimator is decreased in this case. It can be seen that the response performance of the system is good even though the parameter variation is not adapted on line.

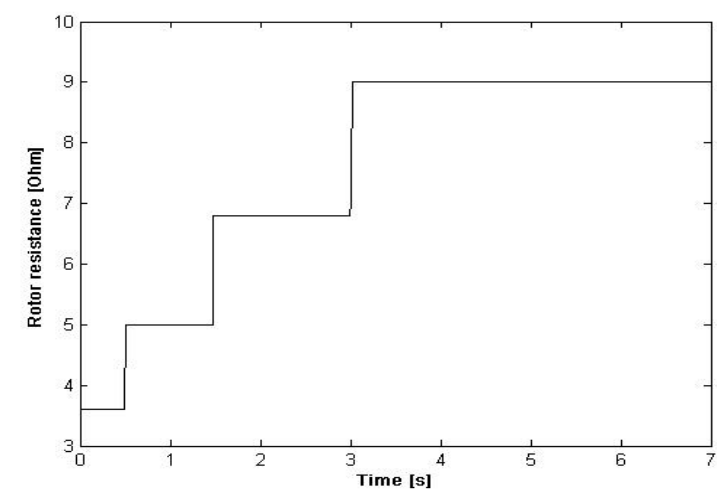

Fig. 5. Rotor resistance variations
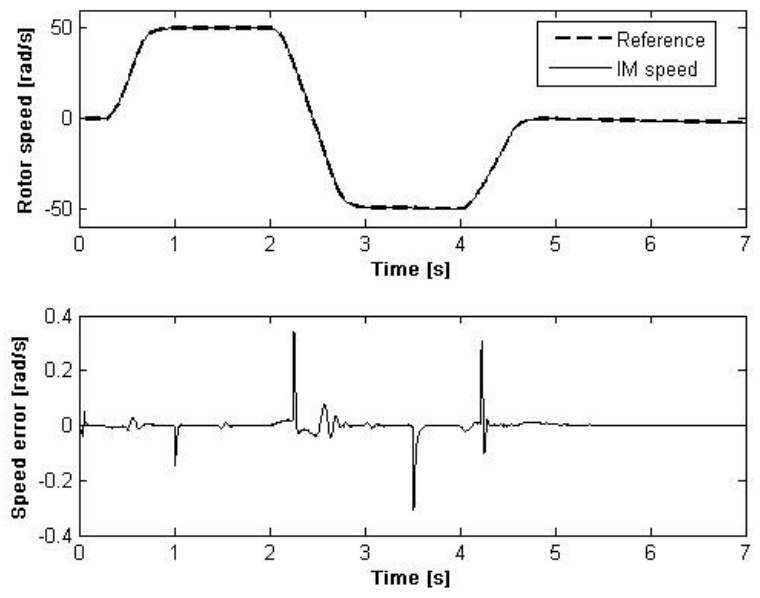

Fig. 6. Rotor speed and speed error responses of induction motor drive of mismatched model
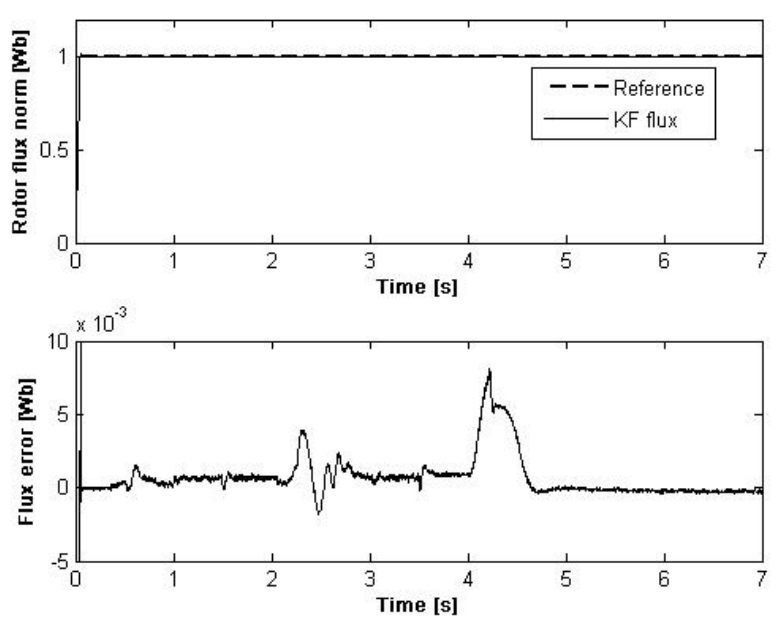

Fig. 7. Rotor flux norm and flux error responses of induction motor drive of mismatched model

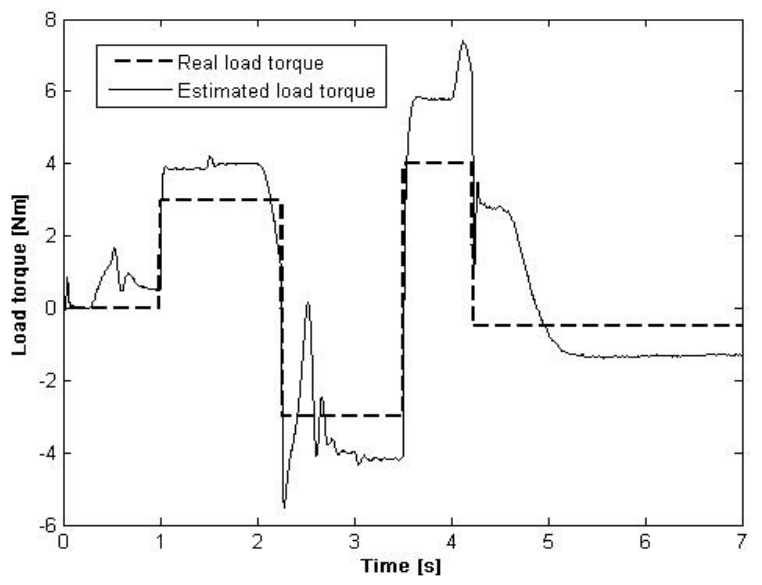

Fig. 8. Load torque estimation for mismatched model

\section{CONCLUSION}

A cascaded nonlinear predictive control algorithm with a load torque disturbance observer of an induction motor drive has been proposed. The nonlinear predictive controller is developed for multivariable system of the induction motor in order to track electromagnetic torque and rotor flux norm. It constitutes the inner loop of the system. The external loop is dedicated to speed tracking with a simple predictive controller. It has been shown that this kind of control is effective for solving the control problem of induction machines. Although the predictive control belongs to optimal control, it does not need an online optimization and trajectories tracking is successfully achieved. The load torque disturbance, considered as unknown, is estimated by a simple observer and has a PI structure. Faster load torque disturbance compensation is guaranteed, and robustness with respect to machine parameter is enhanced with this cascade structure control design. An appropriate and simple choice of the tuning parameters provides a robust controller, very well adapted for trajectories tracking problem. 


\section{APPENDIX}

TABLE I

MACHINE AND CONTROLLER PARAMETERS

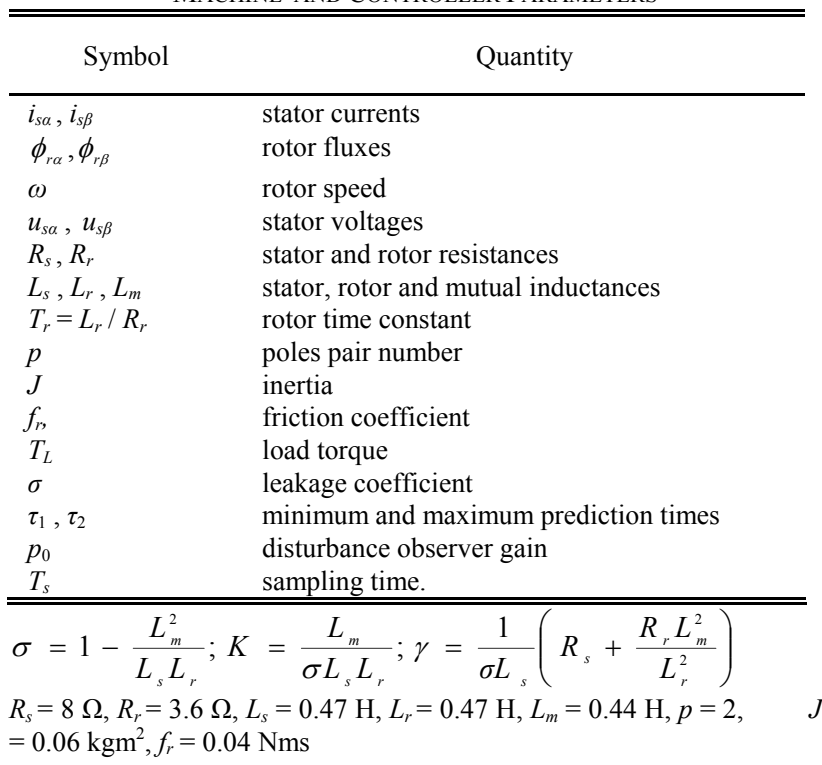

\section{REFERENCES}

[1] F. Blaschke, "The principle of field orientation applied to the new transvector closed loop system for rotating field machines," Siemens Rev., 34, pp. 217-220, 1972

[2] M. Barut, S. Bogosyan and M. Gokasan, "Speed sensorless direct torque control of IM's with rotor resistance estimation," Energy Conversion and Management, 46, pp. 335-349, 2005.

[3] F. Chen, and M.W. Dunnigan, "A new non-linear sliding-mode for an induction motor machine incorporating a sliding-mode flux observer," International Journal of Robust and Nonlinear Control, 14, pp. 463-486, 2003.
[4] J. Chiasson, "Nonlinear controllers for an induction motor," Control Engeineering Practice, vol.4, no.7, pp. 977-990, 1996.

[5] C.E. Garcia, D.M. Prett and M. Morari, "Model predictive control: theory and practice- a survey," Automatica, 3, pp. 335-348, 1989

[6] J. Richalet, "Industrial Applications of Model Based Predictive Control," Automatica, vol. 29, no. 5, pp. 1251-1274, 1993.

[7] C. Bordons, and E.F Camacho, "A generalized predictive controller for a wide class of industrial processes," IEEE Transactions on Control Systems Technology, 6, no. 3, pp. 372-387, 1998.

[8] L. Ping, "Optimal Predictive Control of Continuous Nonlinear Systems," International Journal of Control, vol. 63, no. 1, pp. 633649, 1996

[9] W.-H. Chen, D.J. Balance and P.J. Gawthrop, "Optimal Control of Nonlinear Systems: A Predictive Control Approach," Automatica, vol. 39, no. 4, pp. 633-641, 2003.

[10] W.-H. Chen, D.J. Balance, P.J. Gawthrop, J.J. Gribble and J. O'Reilly, "Nonlinear PID predictive controller," IEE Proceedings Control Theory application, vol. 146, no. 6, pp. 603-611, 1999.

[11] W. Feng, J. O'Reilly and D.J. Balance, "MIMO Nonlinear PID Predictive Controller," IEE Proceedings Control Theory application, vol. 149, no. 3, pp. 203-208, 2002.

[12] D. Dumur, P. Boucher and J. Röder, "Design of an open architecture structure for implementation of predictive controllers for motors," IEEE Conference on Control Applications, Trieste, Italy, pp. 1307-1311, 1998.

[13] M.K. Maaziz, P. Boucher and D. Dumur, "A New Control Strategy for Induction Motor Based on Non-linear Predictive Control and Feedback Linearization," International Journal of adaptive Control and Signal Processing, 14, pp. 313-329, 2000.

[14] R. Hedjar , R. Toumi , P. Boucher and D. Dumur, "Two Cascaded Nonlinear Predictive Controls of Induction Motor," IEEE Conference on Control Applications, vol. 1, Istanbul, Turkey, pp. 458-463, 2003.

[15] A. Merabet, M. Ouhrouche, R-T. Bui and J. Thongam, "Nonlinear multivariable control of induction motor based on generalized predictive control," $8^{\text {th }}$ IASTED International Conference Control and Applications, Montreal, Canada, pp. 07-12, 2006. 